\title{
Obesity is Not Associated with Increased Short-term Complications After Primary Total Shoulder Arthroplasty
}

\author{
Jimmy J. Jiang MD, Jason R. Somogyi MD, Pranay B. Patel MD, \\ Jason L. Koh MD, Douglas R. Dirschl MD, Lewis L. Shi MD
}

Received: 14 June 2015/Accepted: 30 September 2015/Published online: 9 October 2015

(C) The Association of Bone and Joint Surgeons (R 2015

\begin{abstract}
Background Few studies have analyzed the association between elevated BMI and complications after total shoulder arthroplasty (TSA). Previous studies have not consistently arrived at the same conclusion regarding whether obesity is associated with a greater number of postoperative complications. We used a national surgical database to compare the 30-day complication profile and hospitalization outcomes after primary TSA among patients in different BMI categories.

Questions/purposes We asked:(1) Is obesity associated with an increased risk of complications within 30 days of

Each author certifies that he or she, or a member of his or her immediate family, has no funding or commercial associations (eg, consultancies, stock ownership, equity interest, patent/licensing arrangements, etc) that might pose a conflict of interest in connection with the submitted article.

All ICMJE Conflict of Interest Forms for authors and Clinical Orthopaedics and Related Research ${ }^{\mathbb{R}}$ editors and board members are on file with the publication and can be viewed on request.

Each author certifies that his or her institution approved or waived approval for the human protocol for this investigation and that all investigations were conducted in conformity with ethical principles of research

This study was performed at Department of Orthopaedic Surgery and Rehabilitation Medicine at the University of Chicago.
\end{abstract}

J. J. Jiang, J. R. Somogyi, P. B. Patel, J. L. Koh, D. R. Dirschl, L. L. Shi $(\bowtie)$

Department of Orthopaedic Surgery and Rehabilitation

Medicine, The University of Chicago, 5841 S Maryland Avenue,

MC 3079, Chicago, IL 60637, USA

e-mail: 1shi@bsd.uchicago.edu

\section{J. L. Koh}

Department of Orthopaedic Surgery, NorthShore University HealthSystem, Evanston, IL, USA primary TSA? (2) Is obesity associated with increased operative time?

Methods The American College of Surgeons National Surgical Quality Improvement Program ${ }^{\mathbb{R}}$ database for 2006 to 2012 was queried to identify all patients who underwent a primary TSA for osteoarthritis of the shoulder. The ACS-NSQIP ${ }^{\circledR}$ database was selected for this study as it is a nationally representative database that provides prospectively collected perioperative data and a comprehensive patient medical profile. Exclusion criteria included revision TSA, infection, tumor, or fracture. We analyzed 4796 patients who underwent a primary TSA for osteoarthritis of the shoulder. Patients who underwent a TSA were divided in four BMI categories: normal (18.5-25 $\mathrm{kg} / \mathrm{m}^{2}$ ), overweight $\left(25-30 \mathrm{~kg} / \mathrm{m}^{2}\right)$, obesity Class $1(30-35$ $\mathrm{kg} / \mathrm{m}^{2}$ ), and obesity Class 2 or greater $\left(>35 \mathrm{~kg} / \mathrm{m}^{2}\right.$ ). Perioperative hospitalization data and 30-day postoperative complications were compared among different BMI classes. Differences in patient demographics, preoperative laboratory values, and preexisting patient comorbidities also were analyzed among different BMI groups, and multivariate analysis was used to adjust for any potential confounding variables.

Results There was no association between BMI and 30-day complications after surgery (normal as reference, overweight group relative risk: 0.57 [95\% CI, 0.30-1.06], $\mathrm{p}$ $=0.076$; obesity Class 1 relative risk: 0.52 [95\% CI, 0.261.03], $\mathrm{p}=0.061$; obesity Class 2 or greater relative risk: 0.54 [95\% CI, 0.25-1.17], $\mathrm{p}=0.117$ ). However, greater BMI was associated with longer surgical times (for normal BMI control group: 110 minutes, SD, 42 minutes; overweight group: 115 minutes, SD, 46 minutes, mean difference to control: 5 minutes [95\% CI, -1 to $10 \mathrm{~min}$ utes], $\mathrm{p}=0.096$; obesity Class 1: 120 minutes, SD, 43 minutes, mean difference: 10 minutes [95\% CI, 5-15 
minutes], $\mathrm{p}<0.001$; obesity Class 2 or greater: 122 minutes, SD, 45 minutes, mean difference: 12 minutes [95\% CI, 6-18 minutes], $\mathrm{p}<0.001$ ).

Conclusions Although the surgical time increased for patients with greater BMI, the 30-day complications and perioperative hospitalization data after TSA were not different in patients with increased BMI levels. Obesity alone should not be a contraindication for TSA, and obese patients can expect similar incidences of postoperative complications. The preoperative medical optimization plan should be consistent with that of patients who are not obese who undergo TSA.

Level of Evidence Level III, therapeutic study.

\section{Introduction}

Total shoulder arthroplasty (TSA) is an effective operation for pain relief and functional improvement in patients limited by shoulder arthritis who have not received adequate relief with nonoperative management. Since the first documented shoulder arthroplasty was performed in 1893, as reported by Bankes and Emery [4], the number of TSAs performed in the United States is expected to continue to increase steadily $[11,18]$. Obesity affects a large proportion of the population in the United States, with an estimated prevalence of $36 \%$ [12]. The WHO defines obesity as a BMI greater than $30 \mathrm{~kg} / \mathrm{m}^{2}$ [32]. The concern for obesity is particularly evident in our aging population in the United States where $71 \%$ of inhabitants older than 60 years are classified as either overweight or obese [26]. Because older patients who are obese make up a large proportion of patients undergoing elective orthopaedic surgery [7], there is concern regarding the association of obesity and postoperative complications in elective orthopaedic surgical procedures such as shoulder arthroplasty.

Obesity also has been associated with increased difficulty with exposure and longer operative times during lower extremity arthroplasties $[2,16,23]$. However, studies of TSAs have disagreed regarding whether obesity is associated with increased postoperative complications. Linberg et al. [24] reported that patients who are morbidly obese have a greater incidence of unsatisfactory results after TSA. However, a review of upper extremity surgery concluded that patients who are obese are not at increased risk of complications compared with patients who are not obese [25]. Singh et al. [28] reported that higher BMI was actually protective against postoperative mortality after primary shoulder arthroplasty.

We therefore asked: (1) Is obesity associated with an increased risk of complications within 30 days of primary TSA? (2) Is obesity associated with increased operative time?

\section{Patients and Methods}

The American College of Surgeons National Surgical Quality Improvement Program ${ }^{\circledR}$ (ACS NSQIP ${ }^{\circledR}$ ) database [1] was analyzed from 2006 to 2013 for all patients who underwent a primary TSA (Current Procedural Terminology code 23472), including anatomic TSA and reverse TSA. The ACS-NSQIP ${ }^{\circledR}$ is a prospectively maintained database that contains perioperative data on randomly assigned patients undergoing procedures across all surgical specialties at participating institutions [1]. Surgical clinical reviewers are employed by each participating hospital to manage clinical information in the database, collect each patient's medical history before surgery, and observe postoperative morbidity and mortality associated with each surgical procedure. Patients are contacted postoperatively by telephone or in writing to confirm 30-day complications and outcomes. The ACS-NSQIP ${ }^{\circledR}$ applies strict definitions, which are described in detail in the user guide, in the documentation of patient comorbidities and complications [1]. The total number of different surgical cases (orthopaedic, plastic, general surgery, otolaryngology, gynecology, and urology) available from this database range from more than 150,000 in 2006 to more than 600,000 in 2013. More than 200 Health Insurance Portability and Accountability Act-compliant variables are collected for each patient encounter. The use of the ACSNSQIP ${ }^{\circledR}$ database is appropriate for our study as it is a nationally representative database that provides prospectively collected perioperative data, along with relatively comprehensive demographic and medical profiles of patients.

Approval from our institutional review board was obtained before the start of our study. Patients were excluded from this study if they had a BMI less than $18.5 \mathrm{~kg} / \mathrm{m}^{2}$, lacked documented preoperative height and weight, or had previous shoulder hardware (ICD-9 codes 996.4x, 996.6x, 996.7x), fracture (ICD-9 codes 812.xx, 733.8x), pathologic fracture (ICD-9 code 733.11), tumor (ICD-9 codes 170.4, 213.4), or associated infection (ICD-9 code 730.xx). Patients who underwent a TSA initially were divided in six BMI categories as defined by the WHO [32]: normal $\left(18.5-25 \mathrm{~kg} / \mathrm{m}^{2}\right)$, overweight $\left(25-30 \mathrm{~kg} / \mathrm{m}^{2}\right)$, obesity Class $1\left(30-35 \mathrm{~kg} / \mathrm{m}^{2}\right)$, obesity Class 2 or greater $\left(35-40 \mathrm{~kg} / \mathrm{m}^{2}\right)$, morbid obesity (> $\left.40 \mathrm{~kg} / \mathrm{m}^{2}\right)$, and superobese $\left(>50 \mathrm{~kg} / \mathrm{m}^{2}\right)$. Morbid obesity and superobese BMI groups had few cases, and our study would have been underpowered to identify differences in complications between either of these groups compared with the control group. Thus, final analysis was performed with four BMI categories: normal $\left(18.5-25 \mathrm{~kg} / \mathrm{m}^{2}\right)$, overweight (25$\left.30 \mathrm{~kg} / \mathrm{m}^{2}\right)$, obesity Class $1\left(30-35 \mathrm{~kg} / \mathrm{m}^{2}\right)$, and obesity Class 2 or greater $\left(>35 \mathrm{~kg} / \mathrm{m}^{2}\right)$. Perioperative hospitalization data, 30-day postoperative complications, demographics, 
Table 1. Comparison of complications among patients with different BMI

\begin{tabular}{|c|c|c|c|c|c|}
\hline \multirow[t]{2}{*}{ 30-day postoperative morbidity and mortality } & \multicolumn{4}{|c|}{ BMI $\left(\mathrm{kg} / \mathrm{m}^{2}\right)$} & \multirow[t]{2}{*}{$\mathrm{p}$ value } \\
\hline & $18.5-25$ & $25-30$ & $30-35$ & $>35$ & \\
\hline \multicolumn{6}{|l|}{ Wound complications (\%) } \\
\hline Superficial infection & 0 & 0.1 & 0.3 & 0.2 & 0.362 \\
\hline Deep infection & 0.1 & 0.1 & 0.1 & 0 & 0.762 \\
\hline Dehiscence & 0.1 & 0 & 0.2 & 0 & 0.263 \\
\hline Total wound complications & 0.3 & 0.1 & 0.4 & 0.2 & 0.488 \\
\hline \multicolumn{6}{|l|}{ Respiratory complications (\%) } \\
\hline Pneumonia & 0.4 & 0.5 & 0.6 & 0.2 & 0.544 \\
\hline Reintubation & 0 & 0.1 & 0.1 & 0.1 & 0.801 \\
\hline Ventilator $>48$ hours & 0.1 & 0.1 & 0.1 & 0.1 & 0.968 \\
\hline \multicolumn{6}{|l|}{ Cardiac complications $(\%)$} \\
\hline Cardiac arrest & 0 & 0.1 & 0 & 0.1 & 0.493 \\
\hline Myocardial infarction & 0.4 & 0.3 & 0.3 & 0.1 & 0.685 \\
\hline \multicolumn{6}{|l|}{ Renal complications (\%) } \\
\hline Progressive renal insufficiency & 0 & 0 & 0.2 & 0.1 & 0.312 \\
\hline Acute renal failure requiring hemodialysis & 0 & 0 & 0.1 & 0 & 0.425 \\
\hline \multicolumn{6}{|l|}{ Neurologic complications $(\%)$} \\
\hline Cerebrovascular accident & 0.1 & 0.3 & 0.1 & 0 & 0.337 \\
\hline Coma & 0 & 0 & 0 & 0 & - \\
\hline Peripheral nerve injuries & 0.4 & 0.3 & 0 & 0 & 0.068 \\
\hline Urinary tract infection $(\%)$ & 1.5 & 0.8 & 0.6 & 1.3 & 0.158 \\
\hline Deep vein thrombosis $(\%)$ & 0.7 & 0.1 & 0.3 & 0.7 & 0.063 \\
\hline Pulmonary embolism (\%) & 0.5 & 0.2 & 0.4 & 0.4 & 0.613 \\
\hline \multicolumn{6}{|l|}{ Systemic complications (\%) } \\
\hline Sepsis & 0.3 & 0.2 & 0.2 & 0.2 & 0.979 \\
\hline Septic Shock & 0 & 0.1 & 0.1 & 0 & 0.716 \\
\hline Blood transfusions $(\%)$ & 6 & 3.6 & 3.6 & 2.3 & 0.001 \\
\hline Return to operating room $(\%)$ & 1.4 & 0.6 & 0.7 & 0.7 & 0.260 \\
\hline Death $(\%)$ & 0 & 0.1 & 0.3 & 0.2 & 0.545 \\
\hline Patients with at least one complication (\%) & 5 & 3 & 3 & 4 & 0.128 \\
\hline
\end{tabular}

comorbidities, and preoperative laboratory values were compared among patients in different BMI classes.

A total of 4796 patients who underwent primary TSA were identified from the ACS-NSQIP ${ }^{\circledR}$ database from 2006 to 2013. After applying our exclusion criteria, 4267 were included for final analysis in this study. Subgroup analysis showed that there were $738,1463,1126$, and 940 patients in the normal, overweight, obesity Class 1, and obesity Class 2 or greater groups, respectively. This represents an overall population where $47 \%$ of the patients are obese.

The proportion of patients with at least one postoperative complication within 30 days of surgery was calculated and compared among different BMI groups (Table 1). The overall incidence of complications was comprised from a list of individual complications grouped in a systems-based classification. Medical complications investigated included deep venous thrombosis, pulmonary embolism, urinary tract infection, and wound, respiratory, cardiac, neurologic, renal, and systemic complications. The proportion of patients who returned to the operating room or who died within 30 days also were included in the complication analysis.

Mean operative time was compared among the BMI groups (Table 2). Other perioperative data analyzed included type of anesthesia administered, resident or fellow involvement, history of another surgery 30 days before the index procedure, time of admission to surgery, length of hospital stay after surgery, proportion of patients requiring a blood transfusion, and percentage of patients discharged to home.

Other potential confounding variables were considered and adjusted for in this study. Demographic data (Table 3) 
Table 2. Comparison of hospitalization outcomes

\begin{tabular}{|c|c|c|c|c|c|}
\hline \multirow[t]{2}{*}{ Perioperative data } & \multicolumn{4}{|c|}{ BMI $\left(\mathrm{kg} / \mathrm{m}^{2}\right)$} & \multirow[t]{2}{*}{$\mathrm{p}$ value } \\
\hline & $18.5-25$ & $25-30$ & $30-35$ & $>35$ & \\
\hline \multicolumn{6}{|c|}{ Surgical time (minutes) } \\
\hline Mean & 110 & 115 & 120 & 122 & \multirow[t]{2}{*}{$<0.001$} \\
\hline SD & 42 & 46 & 43 & 45 & \\
\hline \multicolumn{6}{|c|}{ General anesthesia $(\%)$} \\
\hline Yes & 95 & 95 & 96 & 97 & \multirow[t]{2}{*}{0.056} \\
\hline No & 5 & 5 & 4 & 3 & \\
\hline \multicolumn{6}{|c|}{ Resident or fellow involvement (\%) } \\
\hline Yes & 54 & 55 & 57 & 57 & \multirow[t]{2}{*}{0.810} \\
\hline No & 46 & 45 & 43 & 43 & \\
\hline \multicolumn{6}{|c|}{ Another surgery within 30 days prior (\%) } \\
\hline Yes & $<1$ & 0 & $<1$ & $<1$ & \multirow[t]{2}{*}{0.236} \\
\hline No & 99.4 & 100.0 & 99.8 & 99.5 & \\
\hline \multicolumn{6}{|c|}{ Time from admission to surgery (days) } \\
\hline Mean & 0 & 0 & $<1$ & $<1$ & \multirow[t]{2}{*}{0.452} \\
\hline SD & $<1$ & $<1$ & 11 & $<1$ & \\
\hline \multicolumn{6}{|c|}{ Postoperative length of stay (days) } \\
\hline Mean & 2.1 & 2.1 & 2.0 & 2.1 & \multirow[t]{2}{*}{0.423} \\
\hline SD & 1.4 & 2.9 & 1.2 & 1.2 & \\
\hline \multicolumn{6}{|c|}{ Total hospital stay (days) } \\
\hline Mean & 2.1 & 2.1 & 2.0 & 2.1 & \multirow[t]{2}{*}{0.340} \\
\hline SD & 1.4 & 2.9 & 1.2 & 1.2 & \\
\hline \multicolumn{6}{|c|}{ Home discharge $(\%)$} \\
\hline Yes & 63 & 67 & 69 & 66 & \multirow[t]{2}{*}{0.050} \\
\hline No & 37 & 33 & 31 & 34 & \\
\hline \multicolumn{6}{|c|}{ Blood transfusion $(\%)$} \\
\hline Yes & 6 & 4 & 4 & 2 & \multirow[t]{2}{*}{0.001} \\
\hline No & 94 & 96 & 96 & 98 & \\
\hline
\end{tabular}

analyzed for all patients included age, sex, race, BMI, current smoking history, current alcohol use (more than two drinks daily for at least 2 weeks before surgery), and preoperative level of function. Common preoperative laboratory values (Table 4) reviewed include white blood count, creatinine, hematocrit, international normalized ratio, and albumin. The prevalence of medical comorbidities (Table 4) analyzed including prevalence of diabetes, hypertension requiring medication, congestive heart failure, chronic obstructive pulmonary disease, dyspnea, peripheral vascular disease, heart disease requiring a previous cardiac procedure, cerebrovascular accident or transient ischemic attack, bleeding disorder, current steroid use, current chemotherapy, or radiation therapy also were compared among the different BMI groups. In addition, wound classification (clean versus not clean) and American Society of Anesthesiologists physical status classification were compared among the BMI groups.

\section{Statistical Analysis}

In this retrospective study, we compared demographics, comorbidities, complications, and perioperative outcomes data using ANOVA for all continuous variables and Pearson's chi-square tests for all categorical variables. Patient factors with significant differences ( $p$ value $<0.10$ ) in the univariate analysis (Tables 3 and 4) then were included as variables in the multivariate model (Table 5) to analyze whether BMI was independently associated with short-term complications and outcomes. The group of patients with a normal BMI was used as the reference group in the multivariate analyses, and a $\mathrm{p}$ value of 0.05 or less was considered to be statistically significant. A post hoc power analysis was performed using the case distribution, total number of patients, and overall incidence of complications in this study. A statistical power of $80 \%$ with an alpha value of 0.05 was found to detect a $3 \%$ difference 
Table 3. Comparison of demographics among patients

\begin{tabular}{|c|c|c|c|c|c|}
\hline \multirow[t]{2}{*}{ Demographics } & \multicolumn{4}{|c|}{ BMI $\left(\mathrm{kg} / \mathrm{m}^{2}\right)$} & \multirow[t]{2}{*}{$\mathrm{p}$ value } \\
\hline & $18.5-25$ & $25-30$ & $30-35$ & $>35$ & \\
\hline \multicolumn{6}{|l|}{ Age (years) } \\
\hline Mean & 72 & 71 & 69 & 67 & \multirow[t]{2}{*}{$<0.001$} \\
\hline SD & 11 & 10 & 10 & 9 & \\
\hline \multicolumn{6}{|l|}{$\operatorname{Sex}(\%)$} \\
\hline Male & 33 & 51 & 49 & 38 & \multirow[t]{2}{*}{$<0.001$} \\
\hline Female & 67 & 49 & 51 & 62 & \\
\hline \multicolumn{6}{|l|}{ Race $(\%)$} \\
\hline White or Hispanic & 86 & 85 & 89 & 84 & \multirow[t]{5}{*}{$<0.001$} \\
\hline Black & 3 & 3 & 3 & 7 & \\
\hline Asian & 2 & $<1$ & $<1$ & $<1$ & \\
\hline American Indian & $<1$ & $<1$ & $<1$ & $<1$ & \\
\hline Other/unknown & 8 & 11 & 8 & 9 & \\
\hline \multicolumn{6}{|l|}{ Current smoker (\%) } \\
\hline Yes & 90 & 91 & 92 & 91 & \multirow[t]{2}{*}{0.465} \\
\hline No & 10 & 8 & 9 & 10 & \\
\hline \multicolumn{6}{|c|}{ Current alcohol abuse (\%) } \\
\hline Yes & 4 & 2 & 3 & 2 & \multirow[t]{2}{*}{0.191} \\
\hline No & 96 & 98 & 97 & 98 & \\
\hline \multicolumn{6}{|l|}{ Preoperative function (\%) } \\
\hline Independent & 96 & 97 & 98 & 96 & \multirow[t]{3}{*}{0.015} \\
\hline Partially independent & 4 & 3 & 2 & 4 & \\
\hline Totally dependent & $<1$ & $<1$ & $<1$ & $<1$ & \\
\hline
\end{tabular}

in the overall incidence of complications between the highest BMI group (obesity Class 2 or greater) and the normal BMI group (control group). All data analysis and statistical calculations were performed using SPSS, Version 17 (Chicago, IL, USA).

\section{Results}

There was no association between BMI and complications after surgery (Table 5). Using the normal BMI group as reference, the overweight group had a relative risk of complications at 0.57 (95\% CI, 0.30-1.06; p = 0.076), obesity Class 1 had a relative risk of 0.52 (95\% CI, 0.26$1.031 ; \mathrm{p}=0.061$ ), and obesity Class 2 or greater had a relative risk of 0.54 (95\% CI, $0.25-1.17 ; \mathrm{p}=0.117)$.

Increased BMI was associated with longer surgical times (Table 5). For the normal BMI group, surgical time was 110 minutes (SD, 42 minutes). The overweight group had an operative time of 114 minutes (SD), which was not greater than that of the normal BMI comparison group (mean difference, 115; SD, 46 minutes; mean difference to control, 5 minutes; $95 \% \mathrm{CI},-1$ to 10 minutes; $\mathrm{p}=0.096$ ).
However, patients in obesity Class 1 group had a longer surgical time of 120 minutes (SD, 43 minutes; mean difference, 10 minutes; 95\% CI, 5-15 minutes; $\mathrm{p}<0.001$ ). The patients in obesity Class 2 or greater had a longer surgical time of 122 minutes (SD, 45 minutes; mean difference, 12 minutes; 95\% CI, 6-18 minutes; $\mathrm{p}<0.001$ ).

\section{Discussion}

The purpose of this study was to compare the perioperative hospitalization data and 30-day postoperative complications in patients undergoing a primary TSA among different BMI classes. Overall our study cohort revealed $47 \%$ of patients undergoing TSA were obese, which is consistent with national averages [7, 12, 26]. Investigations regarding the effects and outcomes of lower extremity arthroplasty have shown a greater proportion of complications in patients who are obese compared with those who are not obese [16, 17]. However, the association of BMI and higher complications in lower extremity surgery cannot be directly correlated to the surgeries performed in the upper extremity [25]. Thus, the large sample size and 
Table 4. Comparison of laboratory values and comorbidities among patients

\begin{tabular}{|c|c|c|c|c|c|}
\hline \multirow[t]{2}{*}{ Preoperative laboratory tests and comorbidities } & \multicolumn{4}{|c|}{ BMI $\left(\mathrm{kg} / \mathrm{m}^{2}\right)$} & \multirow[t]{2}{*}{$\mathrm{p}$ value } \\
\hline & $18.5-25$ & $25-30$ & $30-35$ & $>35$ & \\
\hline \multicolumn{6}{|l|}{ White blood cell count } \\
\hline Mean & 7 & 7 & 7 & 7 & \multirow[t]{2}{*}{$<0.001$} \\
\hline SD & 2 & 3 & 2 & 3 & \\
\hline \multicolumn{6}{|l|}{ Creatinine } \\
\hline Mean & 0.9 & 1.0 & 1.0 & 1.0 & \multirow[t]{2}{*}{$<0.001$} \\
\hline SD & 0.4 & 0.6 & 0.4 & 0.7 & \\
\hline \multicolumn{6}{|l|}{ Hematocrit } \\
\hline Mean & 40 & 40 & 41 & 41 & \multirow[t]{2}{*}{$<0.004$} \\
\hline SD & 4 & 5 & 4 & 4 & \\
\hline \multicolumn{6}{|l|}{ International normalized ratio } \\
\hline Mean & 1.1 & 1.1 & 1.1 & 1.0 & \multirow[t]{2}{*}{0.611} \\
\hline SD & 0.3 & 0.5 & 0.3 & 0.3 & \\
\hline \multicolumn{6}{|l|}{ Albumin } \\
\hline Mean & 4.1 & 4.1 & 4.1 & 4.0 & \multirow[t]{2}{*}{0.009} \\
\hline SD & 0.5 & 0.4 & 0.4 & 0.4 & \\
\hline \multicolumn{6}{|l|}{ Wound classification (\%) } \\
\hline Clean & 99 & 98 & 99 & 99 & \multirow[t]{2}{*}{0.301} \\
\hline Not clean & 1 & 2 & 1 & 1 & \\
\hline \multicolumn{6}{|l|}{ ASA class $(\%)$} \\
\hline 1 or 2 & 56 & 57 & 52 & 35 & \multirow[t]{3}{*}{$<0.001$} \\
\hline 3 & 42 & 41 & 46 & 61 & \\
\hline 4 & 2 & 2 & 2 & 4 & \\
\hline Diabetes (\%) & 8 & 12 & 18 & 27 & $<0.001$ \\
\hline Hypertension (\%) & 56 & 65 & 80 & 69 & $<0.001$ \\
\hline Congestive heart failure (\%) & 1 & $<1$ & $<1$ & 1 & 0.050 \\
\hline \multicolumn{6}{|l|}{ Dyspnea (\%) } \\
\hline At rest & 1 & $<1$ & 1 & 1 & \multirow[t]{3}{*}{0.001} \\
\hline Moderate exertion & 5 & 6 & 6 & 11 & \\
\hline No & 94 & 94 & 93 & 88 & \\
\hline Cardiac surgery or stent $(\%)$ & 5 & 6 & 5 & 5 & 0.441 \\
\hline Chronic obstructive pulmonary disease $(\%)$ & 6 & 5 & 5 & 6 & 0.453 \\
\hline Peripheral vascular disease $(\%)$ & 0 & 1 & 1 & $<1$ & 0.479 \\
\hline Cerebrovascular accident or transient ischemic attack (\%) & 10 & 6 & 4 & 6 & 0.004 \\
\hline Ascites (\%) & $<1$ & 0 & $<1$ & 0 & 0.425 \\
\hline Bleeding disorder $(\%)$ & 3 & 3 & 3 & 3 & 0.629 \\
\hline Steroid use $(\%)$ & 7 & 4 & 5 & 4 & 0.008 \\
\hline Chemotherapy (\%) & 0 & $<1$ & 0 & $<1$ & 0.602 \\
\hline Radiation (\%) & 0 & 0 & 0 & 0 & - \\
\hline
\end{tabular}

ASA $=$ American Society of Anesthesiologists.

national representation of this study provide additional evidence to suggest that increased BMI is not associated with increased short-term complications in patients undergoing primary TSA. The complications analyzed including mortality, deep venous thrombosis, pulmonary embolism, pneumonia, cardiac complications, neurologic complications, wound complications, and sepsis were low $(<1 \%)$ in our study cohort. Only the percentage of urinary tract infections was found to be greater than $1 \%$ collectively. This suggests that primary TSA remains a safe 
Table 5. Adjusted comparison of complications and hospitalization outcomes*

\begin{tabular}{|c|c|c|c|c|c|}
\hline \multirow[t]{2}{*}{ Outcomes and complications } & \multirow[t]{2}{*}{ BMI $\left(\mathrm{kg} / \mathrm{m}^{2}\right)$} & \multirow[t]{2}{*}{ Relative risk } & \multicolumn{2}{|c|}{$95 \% \mathrm{CI}$} & \multirow[t]{2}{*}{$\mathrm{p}$ value } \\
\hline & & & Lower & Upper & \\
\hline \multicolumn{6}{|l|}{ Any complication } \\
\hline & $25-30$ & 0.57 & 0.30 & 1.06 & 0.076 \\
\hline & $30-35$ & 0.52 & 0.26 & 1.03 & 0.061 \\
\hline & $>35$ & 0.54 & 0.25 & 1.17 & 0.117 \\
\hline \multicolumn{6}{|l|}{ Return to the operating room } \\
\hline & $25-30$ & 0.29 & 0.07 & 1.29 & 0.103 \\
\hline & $30-35$ & 0.56 & 0.14 & 2.23 & 0.408 \\
\hline & $>35$ & 0.58 & 0.12 & 2.89 & 0.504 \\
\hline \multicolumn{6}{|l|}{ Blood transfusions } \\
\hline & $25-30$ & 0.68 & 0.33 & 1.41 & 0.300 \\
\hline & $30-35$ & 0.82 & 0.39 & 1.71 & 0.591 \\
\hline & $>35$ & 0.41 & 0.16 & 1.05 & 0.063 \\
\hline \multicolumn{6}{|l|}{ Discharge to home } \\
\hline & $25-30$ & 1.07 & 0.82 & 1.40 & 0.632 \\
\hline & $30-35$ & 1.34 & 0.95 & 1.84 & 0.073 \\
\hline & $>35$ & 1.06 & 0.78 & 1.46 & 0.703 \\
\hline
\end{tabular}

* Adjusted for all significant differences $(\mathrm{p}<0.10)$; reference group had a normal BMI $\left(18.5-25 \mathrm{~kg} / \mathrm{m}^{2}\right)$.

procedure with low incidences of complications regardless of obesity status.

Our study has some limitations. The design of this study does not permit evaluation of the effect of BMI on functional outcomes, patient satisfaction scores, radiographic analysis, cost analysis, and implant survivorship. The accuracy of documentation of clinical diagnoses, comorbidities, and complications collected in any database can be limited by errors in data entry. However, previous studies of the ACS-NSQIP ${ }^{\circledR}$ database have shown excellent accuracy and quality control because the database relies on clinical data from patients' medical charts gathered by skilled reviewers and does not rely on administrative claims or billing information $[9,10,15,20]$. The integrity of data collected is scrutinized through site visits at participating institutions, conference calls, an annual meeting of participants, and regular auditing. Information from the database also is not specific enough to identify details of surgical complications and specific indications for return to the operating room. Finally, we likely would have observed higher overall complications in our patients if we had a longer followup beyond the 30-day postoperative time available in this database. Previous studies with longer outcomes have shown an earlier plateau in functional improvement and more frequent revisions in patients undergoing TSA [21, 24, 29]. Despite these limitations, we believe the large patient sample size (powered to identify a $3 \%$ or greater difference in overall incidence of complications) and the standardization of prospectively collected clinical variables from this database help quantify the association of BMI on patients' complications after TSA.

Increased BMI was not associated with greater risk of short-term complications in patients undergoing primary TSA. Previous studies have shown inconsistent results regarding the association of obesity on complications in upper extremity arthroplasty [3, 5, 13, 14, 27, 31]. Some smaller reviews have reported an increase in associated complications [3, 5, 14], whereas studies with larger sample sizes have shown no such relationship [13, 27, 31]. In a review of reverse TSAs, Beck et al. [5] found that the coexistence of obesity was associated with increased complications. Similarly, Gupta et al. [14] reported that patients with a BMI greater than $35 \mathrm{mg} / \mathrm{m}^{2}$ had a higher proportion of complications in a retrospective review of 119 patients. Conversely, Waterman et al. [31] and Griffin et al. [13] showed that obesity was not associated with an increased incidence of most complications. Additionally, Baghdadi et al. [3] found a comparable proportion of complications between patients who were obese and those who were not obese undergoing TSA. Our study adds additional data with an even larger patient sample size, along with a standardized followup protocol, to support no short-term differences in complications among patients of different levels of obesity.

Surgical time increased with greater BMI. Although neither Chalmers et al. [8] or Beck et al. [5] found obesity to affect surgical time in a series of patients undergoing TSA and reverse TSA respectively [5, 8], our results are in 
accordance with those of Linberg et al. [24], who reported prolonged operative time in patients who were obese who were undergoing TSA. Similarly, increased operative time has been reported in patients who are obese who are undergoing arthroscopic procedures about the shoulder [30]. However, mean operative time, as stratified by different levels of obesity, have not been reported on a nationwide level for primary TSA. Our results show that patients and physicians can expect a longer operation time for patients with increased BMI levels.

Results of this study, consistent with those of previous studies [6, 22], also showed that preoperative comorbidities were seen more commonly in patients with greater BMI. Although other associated comorbidities are important in preoperative consultation and planning, it is interesting that the differences in incidence of these risk factors among different BMI groups did not result in more short-term complications.

Although surgical time increased for patients with greater BMI, the 30-day complications and perioperative hospitalization data after TSA were not greater in patients with increased BMI than in those with normal BMI. Obesity alone should not be a contraindication for TSA; patients who are obese should be counseled that the incidence of short-term complications is comparable to that for patients who are not obese. We found no evidence that preoperative medical optimization and risk stratification should be adjusted for patients who are obese who are undergoing TSA. It is important for physicians to be aware of this difference in the association of obesity and complications in TSA compared with lower extremity arthroplasty, which has consistently shown higher incidences of short-term complications [16, 17] and longer mean hospital stay [19] in obese patients. We could not analyze patients who were morbidly obese or super obese separately in this study owing to the smaller sample size of patients with a BMI of $40 \mathrm{~kg} / \mathrm{m}^{2}$ or greater. Future studies should investigate whether a separate group consisting of only patients with a BMI of 40 or $50 \mathrm{~kg} / \mathrm{m}^{2}$ or greater may be associated with increased short-term complications compared with patients who are not obese. In addition, future research needs to be performed to better understand the association of obesity on long-term complications, functional outcomes, and implant survival.

\section{References}

1. American College of Surgeons National Surgical Quality Improvement Program. Participant use data file. 2013; http://site. acsnsqip.org/participant-use-data-file. Accessed November 30, 2014.

2. Amin AK, Clayton RA, Patton JT, Gaston M, Cook RE, Brenkel IJ. Total knee replacement in morbidly obese patients: results of a prospective, matched study. J Bone Joint Surg Br. 2006;88:13211326.

3. Baghdadi YM, Veillette CJ, Malone AA, Morrey BF, SanchezSotelo J. Total elbow arthroplasty in obese patients. J Bone Joint Surg Am. 2014;96:e70.

4. Bankes MJ, Emery RJ. Pioneers of shoulder replacement: Themistocles Gluck and Jules Emile Péan. J Shoulder Elbow Surg. 1995;4:259-262.

5. Beck JD, Irgit KS, Andreychik CM, Maloney PJ, Tang X, Harter GD. Reverse total shoulder arthroplasty in obese patients. J Hand Surg Am. 2013;38:965-970.

6. Beck-Nielsen H, Henriksen JE, Vaag A, Hother-Nielsen O. Pathophysiology of non-insulin-dependent diabetes mellitus (NIDDM). Diabetes Res Clin Pract. 1995;28(suppl):S13-25.

7. Bostman OM. Prevalence of obesity among patients admitted for elective orthopaedic surgery. Int J Obes Relat Metab Disord. 1994;18:709-713.

8. Chalmers PN, Gupta AK, Rahman Z, Bruce B, Romeo AA, Nicholson GP. Predictors of early complications of total shoulder arthroplasty. J Arthroplasty. 2014;29:856-860.

9. Cohen ME, Dimick JB, Bilimoria KY, Ko CY, Richards K, Hall BL. Risk adjustment in the American College of Surgeons National Surgical Quality Improvement Program: a comparison of logistic versus hierarchical modeling. J Am Coll Surg. 2009;209:687-693.

10. Cohen ME, Ko CY, Bilimoria KY, Zhou L, Huffman K, Wang X, Liu Y, Kraemer K, Meng X, Merkow R, Chow W, Matel B, Richards K, Hart AJ, Dimick JB, Hall BL. Optimizing ACS NSQIP modeling for evaluation of surgical quality and risk: patient risk adjustment, procedure mix adjustment, shrinkage adjustment, and surgical focus. J Am Coll Surg. 2013;217:336346.e1.

11. Day JS, Lau E, Ong KL, Williams GR, Ramsey ML, Kurtz SM. Prevalence and projections of total shoulder and elbow arthroplasty in the United States to 2015. J Shoulder Elbow Surg. 2010;19:1115-1120.

12. Flegal KM, Carroll MD, Kit BK, Ogden CL. Prevalence of obesity and trends in the distribution of body mass index among US adults, 1999-2010. JAMA. 2012;307:491-497.

13. Griffin JW, Novicoff WM, Browne JA, Brockmeier SF. Morbid obesity in total shoulder arthroplasty: risk, outcomes, and cost analysis. J Shoulder Elbow Surg. 2014;23:1444-1448.

14. Gupta AK, Chalmers PN, Rahman Z, Bruce B, Harris JD, McCormick F, Abrams GD, Nicholson GP. Reverse total shoulder arthroplasty in patients of varying body mass index. $J$ Shoulder Elbow Surg. 2014;23:35-42.

15. Hechenbleikner EM, Makary MA, Samarov DV, Bennett JL, Gearhart SL, Efron JE, Wick EC. Hospital readmission by method of data collection. J Am Coll Surg. 2013;216:1150-1158.

16. Jain NB, Guller U, Pietrobon R, Bond TK, Higgins LD. Comorbidities increase complication rates in patients having arthroplasty. Clin Orthop Relat Res. 2005;435:232-238.

17. Kerkhoffs GM, Servien E, Dunn W, Dahm D, Bramer JA, Haverkamp D. The influence of obesity on the complication rate and outcome of total knee arthroplasty: a meta-analysis and systematic literature review. J Bone Joint Surg Am. 2012;94:1839-1844.

18. Kim SH, Wise BL, Zhang Y, Szabo RM. Increasing incidence of shoulder arthroplasty in the United States. J Bone Joint Surg Am. 2011;93:2249-2254.

19. Kremers HM, Visscher SL, Kremers WK, Naessens JM, Lewallen DG. The effect of obesity on direct medical costs in total knee arthroplasty. J Bone Joint Surg Am. 2014;96:718-724.

20. Lawson EH, Louie R, Zingmond DS, Brook RH, Hall BL, Han L, Rapp M, Ko CY. A comparison of clinical registry versus administrative claims data for reporting of 30-day surgical complications. Ann Surg. 2012;256:973-981. 
21. Li X, Williams PN, Nguyen JT, Craig EV, Warren RF, Gulotta LV. Functional outcomes after total shoulder arthroplasty in obese patients. J Bone Joint Surg Am. 2013;95:e160.

22. Li Z, Bowerman S, Heber D. Health ramifications of the obesity epidemic. Surg Clin North Am. 2005;85:681-701, v.

23. Liabaud B, Patrick DA Jr, Geller JA. Higher body mass index leads to longer operative time in total knee arthroplasty. $J$ Arthroplasty. 2013;28:563-565.

24. Linberg CJ, Sperling JW, Schleck CD, Cofield RH. Shoulder arthroplasty in morbidly obese patients. J Shoulder Elbow Surg. 2009;18:903-906.

25. London DA, Stepan JG, Lalchandani GR, Okoroafor UC, Wildes TS, Calfee RP. The impact of obesity on complications of elbow, forearm, and hand surgeries. J Hand Surg Am. 2014;39:15781584.

26. Ogden CL, Carroll MD, Curtin LR, McDowell MA, Tabak CJ, Flegal KM. Prevalence of overweight and obesity in the United States, 1999-2004. JAMA. 2006;295:1549-1555.

27. Richards J, Inacio MC, Beckett M, Navarro RA, Singh A, Dillon MT, Sodl JF, Yian EH. Patient and procedure-specific risk factors for deep infection after primary shoulder arthroplasty. Clin Orthop Relat Res. 2014;472:2809-2815.

28. Singh JA, Sperling JW, Cofield RH. Ninety day mortality and its predictors after primary shoulder arthroplasty: an analysis of 4,019 patients from 1976-2008. BMC Musculoskelet Disord. 2011;12:231.

29. Singh JA, Sperling JW, Cofield RH. Revision surgery following total shoulder arthroplasty: analysis of 2588 shoulders over three decades (1976 to 2008). J Bone Joint Surg Br. 2011;93:15131517.

30. Warrender WJ, Brown OL, Abboud JA. Outcomes of arthroscopic rotator cuff repairs in obese patients. J Shoulder Elbow Surg. 2011;20:961-967.

31. Waterman BR, Dunn JC, Bader J, Urrea L, Schoenfeld AJ, Belmont PJ Jr. Thirty-day morbidity and mortality after elective total shoulder arthroplasty: patient-based and surgical risk factors. J Shoulder Elbow Surg. 2015;24:24-30.

32. World Health Organization. Global Database on Body Mass Index. Available at: http://apps.who.int/bmi/index.jsp?introPage= intro_3.html. Accessed September 15, 2014. 